\title{
Sex differences in response to exercise heat-stress in the context of the military environment
}

\author{
Invited Review
}

Jo Corbett ${ }^{1}$ (Corresponding author)

Tel: +44(0)2392843084 Fax: +44(0)02392843620 E-mail: jo.corbett@port.ac.uk

Jennifer Wright ${ }^{1}$

E-mail: jennifer.wright@port.ac.uk

Michael J. Tipton ${ }^{1}$

E-mail: michael.tipton@port.ac.uk

${ }^{1}$ Department of Sport and Exercise Sciences

University of Portsmouth

Spinnaker Building

Cambridge Road

Portsmouth

PO1 2ER

Word count: 5202

Key words: Thermal; hot; humid; male; female; environment

Contributorship: All authors contributed to the production and critical revision of this manuscript

Funding: This review is adapted from a review of literature supported by the ASC (Analysis Support Construct) BAE Systems (Operations) Ltd.

Competing interests: None

Study approval: Not required for review of literature 


\section{Key Messages}

Women can now serve in Ground Close Combat (GCC) roles, where they may be required to operate alongside men in hot environments.

The average female soldier may be at a thermoregulatory disadvantage in many hot environments compared to the average male soldier.

Much of the thermoregulatory difference between males and females is due to fitness and anthropometric differences rather than sex, per se.

It is possible that some of these differences may be lessened with appropriate gender free physical employment standards.

Much of the extant literature lacks ecological validity and there are notable gaps in our understanding of a number of key topics in this area. 


\begin{abstract}
Women can now serve in Ground Close Combat (GCC) roles, where they may be required to operate alongside men in hot environments. However, relative to the average male soldier, female soldiers are less aerobically fit, with a smaller surface area $\left(A_{\mathrm{D}}\right)$, lower mass $(\mathrm{m})$ with higher body fat, and a larger $A_{\mathrm{D}} / \mathrm{m}$ ratio. This increases cardiovascular strain, reduces heat exchange with the environment, and causes a greater body temperature increase for a given heat storage, although a large $A_{\mathrm{D}} / \mathrm{m}$ ratio can be advantageous. Physical employment standards for GCC roles might lessen the magnitude of fitness and anthropometric differences, yet even when studies control for these factors, women sweat less than men at high work rates. Therefore, the average female in a GCC role is likely to be at a degree of disadvantage in many hot environments and particularly during intense physical activity in hot-arid conditions, although heat acclimation may mitigate some of this effect. Any thermoregulatory disadvantage may be exacerbated during the mid-luteal phase of the menstrual cycle, although the data are equivocal. Likewise, sex differences in behavioural thermoregulation and cognition in the heat are not well understood. Interestingly, there is often lower reported heat-illness incidence in women, although the extent to which this is influenced by behavioural factors or historic differences in role allocation is unclear. Indeed, much of the extant literature lacks ecological validity and more work is required to fully understand sex differences to exercise heat-stress in a GCC context.
\end{abstract}




\section{Introduction}

Following the publication of the 2016 Interim report on the health risks to women in ground close combat (GCC) roles the exclusion of women from GCC roles was lifted. ${ }^{1}$ As a consequence, women can now serve alongside men in these defence positions. At present, women make up around $9 \%$ of the British Army. ${ }^{2}$ It has been estimated that, in future, approximately 20 women per year will join the Royal Armoured Corps and 10 women per year will join the Infantry; ${ }^{3}$ both of these units were previously affected by the exclusion.

It has been acknowledged that GCC roles can require intense physical activity. ${ }^{3}$ Moreover, given the variety of theatres in which the British Army operates it is likely that soldiers of both sexes will be exposed to hot conditions during GCC roles. It is, therefore, important to understand the extent to which biological sex impacts upon an individual's ability to operate effectively and safely in these environments. Indeed, the 2014 Women in ground close combat review identified the need for further research to be conducted to better understand the physiological implications of the inclusion of women in GCC roles. ${ }^{3}$ Accordingly, this paper presents a brief overview of the current understanding of sex differences in the response to heat exposure, with a particular emphasis on exercise heat-stress in the context of the military environment.

\section{Physical Characteristics}

Within the general population women are typically shorter and lighter, with a smaller surface area than men and a higher body fat percentage. On average, the maximum rate of oxygen uptake $\left(\mathrm{VO}_{2 \max }\right)$ of women is less than men, in absolute terms $\left(\mathrm{L} \cdot \mathrm{min}^{-1}\right)$ and also expressed relative to bodyweight $\left(\mathrm{mL} \cdot \mathrm{kg}^{-1} \cdot \mathrm{min}^{-1}\right),{ }^{4}$ which is more relevant during load-bearing exercise. These population-wide anthropometric data are in keeping with data from British Military cohorts. ${ }^{5}$ Nevertheless, recent data indicates that only $4.5 \%$ of female army recruits met the physical standards required to start Infantry training ${ }^{3}$ and it is possible that women who pass current and future gender-free physical employment standards to undertake GCC roles may be fitter, with a lower fat mass than the average women or military recruits. ${ }^{5}$ This might result in a reduction in the magnitude of differences in fitness and some anthropometric factors between males and females in GCC roles, although it is likely that they may remain less fit and have a higher fat mass, on average, than the majority of their male counterparts in the same roles. These differences are important because they can influence thermoregulation in the heat. ${ }^{67}$ 


\subsection{Anthropometry}

Body mass serves as an internal 'heat sink'. Assuming a given body composition, the change in deep-body temperature $\left(T_{\mathrm{C}}\right)$ for a given heat storage is inversely related to body mass, ${ }^{7}$ and individuals with a greater body mass typically have a smaller increase in deep body temperature $\left(T_{\mathrm{C}}\right)$ during a standard heat stress. ${ }^{6}$ The 'heat sink' is also influenced by body composition. The heat specific capacity of adipose tissue is less than 'lean' tissue $\left(2.51 \mathrm{vs} .3 .65 \mathrm{~J} \cdot \mathrm{g}^{-1} \cdot \mathrm{C}^{-1}\right)$ and individuals with higher body fat will have a greater increase in $T_{\mathrm{C}}$ for a given body mass and change in heat content. ${ }^{7}$ Although the amount of variance in $T_{\mathrm{C}}$ explained by body-fat may be limited, ${ }^{8}$ together these factors likely represent a disadvantage for female soldiers, who are typically lighter with a greater percentage body fat than males. However, body mass also influences metabolic heat production (MHP) during load-bearing exercise at a fixed speed, being lower in lighter individuals than heavier individuals. ${ }^{9}$ This may benefit the average female soldier by reducing their heat loss requirements during this type of exercise.

Body surface area $\left(A_{\mathrm{D}}\right)$ determines the area available for heat exchange with the environment. When other factors are equal (e.g. skin temperature $\left[T_{\text {sk }}\right]$ and wettedness, environmental conditions) heat transfer will be greatest in those with a high $A_{\mathrm{D}}$ and the absolute heat-transfer potential is greatest in individuals with the highest $A_{\mathrm{D}}{ }^{7}$ However, in environments where the ambient temperature exceeds $T_{\mathrm{sk}}$ a large $A_{\mathrm{D}}$ would enable a higher rate of dry heat-gain from the environment, although high wet heat-loss rates might still be possible if the vapour pressure gradient to the environment is favourable. Thus, whether the lower $A_{\mathrm{D}}$ that is typical in females is a disadvantage, or an advantage, will depend on whether the operational environment favours heat loss, or heat gain.

Body surface area to mass $\left(A_{\mathrm{D}} / \mathrm{m}\right)$ ratio is also important. For a given increase in body mass, there is a relatively smaller increase in $A_{\mathrm{D}}$. Consequently, the $A_{\mathrm{D}} / \mathrm{m}$ ratio is typically bigger for small body sizes i.e. females, than large body sizes, i.e. males. Thus, compared to males, females typically have a greater $A_{\mathrm{D}}$ available for heat exchange relative to their 'heat sink'. Moreover, because MHP is typically lower for smaller people during load bearing exercise at a given speed, ${ }^{9}$ when compared to the average male soldier, the average female soldier may also have a greater $A_{\mathrm{D}}$ relative to their heat production. ${ }^{10}$ However, as discussed subsequently, the extent to which these factors are advantageous, or disadvantageous, may depend on the 
ambient conditions. ${ }^{10} 11$ The $A_{\mathrm{D}} / \mathrm{m}$ ratio also influences the thermoeffector pathways for heatloss, as discussed subsequently (section 3.2). ${ }^{12}$

\subsection{Aerobic fitness}

The combination of thermal stress and exercise stress presents a significant challenge to the cardiovascular system, where a finite cardiac output must meet the dual demands of delivering blood to the working muscle to supply oxygen and to the skin for heat dissipation. If all other factors are equal, a given absolute external work rate will elicit a relatively greater cardiovascular strain in an individual with a low $\mathrm{VO}_{2 \max }$, compared to someone with a higher $\mathrm{VO}_{2 \max }$. Blood volume also tends to be smaller in those with low aerobic fitness. ${ }^{13}$ Therefore, in individuals with a low $\mathrm{VO}_{2 \max }$, the cardiovascular strain associated with thermoregulation is greater because increases in skin blood flow represent a relatively larger shift to the peripheral circulation; this may place the average female soldier at a thermoregulatory disadvantage. ${ }^{14}$ Aerobic fitness may also influence sweating and evaporative heat loss, which is lower in those with low aerobic fitness. However, this may only be relevant at high work rates (MHP=500 W) and when $\mathrm{VO}_{2 \max }$ differs to a greater extent $\left(>20 \mathrm{ml} \cdot \mathrm{kg}^{-1} \mathrm{~min}^{-1}\right)$ than is typical between the average male and female soldier. ${ }^{15}$

Designing studies to compare the thermoregulatory responses of groups who typically differ for $\mathrm{VO}_{2 \max }$, such as male and female soldiers, is challenging. Often the same relative exercise intensity $\left(\% \mathrm{VO}_{2 \max }\right)$ is studied. ${ }^{1617} 18$ However, MHP and the associated heat-loss requirements will be less in the group with the lower $\mathrm{VO}_{2 \max }{ }^{19}{ }^{20}$ To avoid this confounding effect, some have compared groups of men and women who are matched for relative $\mathrm{VO}_{2 \max .}{ }^{21}$ However, this can still result in a lower MHP and reduced heat-loss requirement in women, if they have a lower body mass. ${ }^{20}$ Others have matched groups for both relative $\mathrm{VO}_{2 \max }$ and absolute $\mathrm{VO}_{2 \max }$ i.e. matched for aerobic fitness and body mass. ${ }^{12}$ Although this might be appropriate from a mechanistic perspective, matching independent-groups for characteristics that may naturally differ within the military population in question limits the practical relevance of these findings.

In a GCC context anthropometric and fitness differences might be less than in the wider military population and individuals are likely to be expected to perform certain tasks at a specific minimum rate, irrespective of sex. Thus, study designs comparing thermoregulatory responses of male and female soldiers with fitness (and anthropometric) characteristics representative of the GCC population, performing key physical tasks at a defined rate, may 
have the best ecological validity. Although these studies have not been conducted, a number of studies examining sex differences in thermoregulation in the heat have employed walking at a given treadmill speed. ${ }^{1022}$ However, because of the influence of body mass on MHP during weight-bearing exercise the heat-loss requirement will likely be lower in (lighter) women. This would necessitate a reduced thermoeffector response, but would not necessarily reflect a 'true' sex difference, per se. ${ }^{20}$ These important distinctions in study design must be acknowledged when interpreting studies examining sex differences in thermoregulation (see section 3.2).

\section{Thermoregulation}

\subsection{Behavioural}

Behavioural thermoregulation is characterised by behaviours which correct deviations from a 'neutral' body temperature to try and maintain 'thermal pleasure'. ${ }^{23}$ Behavioural thermoregulation is underpinned by thermo-sensation, mediated by the transient receptor potential family of ion channels. These stimulate small-diameter afferent fibers project to lamina I or to the medullary nucleus of the solitary tract, with the output neurons of these regions conveying afferent information to the hypothalamus and brainstem to generate a conscious change in thermal perception. ${ }^{24}$ Perception consists of a discriminative component (i.e. sensation), primarily determined by $T_{\mathrm{sk}}$, and an affective (i.e. (dis)comfort) component, influenced by $T_{\mathrm{C}}$ and $T_{\text {sk. }}$. At rest in the heat thermal (dis)comfort appears to drive behavioral thermoregulation, whereas during exercise the rating of perceived exertion (RPE) may be more relevant. However, when $T_{\mathrm{C}}$ is not noticeably elevated, thermal sensation and comfort influence RPE, whereas sensations related to cardiovascular strain may become more prominent when $T_{\mathrm{C}}$ is elevated. ${ }^{24}$

The literature examining sex differences in behavioural thermoregulation in humans is limited. In thermoneutral environments, women are more sensitive to warm stimuli than men, ${ }^{25}$ and perceive a given thermal stimulus to be hotter. ${ }^{26}$ It might be anticipated that this would lead female soldiers to initiate behavioural thermoregulatory responses earlier than male soldiers, however, the upper temperature-limit of the thermal comfort zone does not differ between sexes. ${ }^{27}$ At present it is clear that further research is required to gain an adequate understanding of any sex differences in behavioral thermoregulation, as well as the relevance, if any, to soldiers operating in GCC roles. 


\subsection{Autonomic}

Cutaneous vasomotion and sudomotion are the autonomically controlled mechanisms for heat-loss. Autonomic thermoeffector activity is mainly determined by afferent information relating to $T_{\mathrm{C}}$ and $T_{\mathrm{sk}}$ i.e. weighted mean body temperature $\left(T_{\mathrm{b}}\right) .{ }^{28}$ Vasomotion represents the initial autonomic thermoregulatory mechanism, whereby cutaneous vasodilatation increases skin blood-flow, facilitating convective heat transfer to the skin. Sweat evaporation is the predominant heat-loss mechanism during exercise in hot environments and when ambient temperature exceeds $T_{\text {sk. }}$ In hot-arid environments the limits of thermal compensability are determined by sweating capacity, but in saturated environments sweating is ineffective due to an insufficient water vapour pressure gradient between the skin and the environment to enable evaporation.

At rest, sweating onset occurs at a higher ambient, ${ }^{29}$ or mean $T_{\mathrm{b}},{ }^{30} 3132$ in women than in men. Sweating sensitivity may also be lower in women. ${ }^{32}$ Together this causes a lower sweat rate in women during resting heat exposure. ${ }^{30}$ Conversely, women may have a greater skin blood flow during passive heating. ${ }^{32}$ Together these data support the assertion that women are more reliant on cutaneous vasodilation and less reliant on sweating than men. ${ }^{30}$ However, these passiveheating studies did not control for anthropometric factors Although this design consideration may be of little practical relevance in a GCC context, the extent to which the differences in these studies are due to sex per-se is unclear. Indeed, irrespective of sex, smaller individuals are more suited to passive heat-loss due to their greater $A_{\mathrm{D}} / \mathrm{m}$ ratio. This enables them to rely more on vasomotor changes to regulate body temperature, such that it may be efficient for the sudomotor threshold to occur at a higher $T_{\mathrm{b}}{ }^{12}$

Many studies examining sex differences in thermoregulation during exercise have examined a standardised relative work rate $\left(\% \mathrm{VO}_{2 \max }\right)$. These typically show women to have a lower sweating rate compared to men. ${ }^{1617182133}$ Lower sweating has also been reported during treadmill walking at a given speed in the heat. ${ }^{1022} 3435$ In contrast, the increase in $T_{\text {re }}$ was either greater in women than men, ${ }^{213}$ or similar, ${ }^{1617} 18$ at a given relative work rate, whereas during treadmill walking the increase was either less in women, ${ }^{22}{ }^{35}$ not different between sexes, ${ }^{34}$ or higher in women than men in a hot-arid environment, and lower in women than men in a hothumid environment. ${ }^{10}$ 
However, as highlighted in Section 2.2, these approaches to standardising work rate can be confound the isolation of sex differences. For example, Schwiening et al. ${ }^{19}$ demonstrated that the sex differences in sweating reported by Ichinose-Kuwahara et al. ${ }^{18}$ could simply be explained by differences in MHP, whereas Gagnon and Kenny ${ }^{36}$ demonstrated that evaporative heat-loss was strongly associated with MHP $\left(r^{2}=0.82\right)$, irrespective of sex. Similarly, the differential effects of environment on increases in $T_{\text {re }}$ reported by Shaprio et al. ${ }^{10}$ may have been influenced by anthropometry. During load bearing exercise in hot-humid conditions, smaller individuals, with a high $A_{\mathrm{D}} / \mathrm{m}$ ratio, produce and store less heat than larger indiviudals: ${ }^{11}$ this could favour smaller, i.e. female, soldiers. However, the beneficial effect of a high $A_{\mathrm{D}} / \mathrm{m}$ ratio is less pronounced under conditions where a greater water vapour pressure gradient exists between the skin and environment and higher sweat rates may be advantageous. Although these are important methodological considerations, they may be of reduced practical relevance in a military context where these anthropometric factors and fitness might differ between the typical male and female soldier. Therefore, some anthropometric characteristics of the average female soldier could be advantageous in hot-humid conditions, although this effect may be lessened within GCC cohorts because of the possibility of less distinct anthropometric and fitness differences between males and females serving in these roles.

Recent studies have controlled for some of these confounding methodological and physiological factors in order to isolate the effects of sex on thermoregulation. Gagnon and Kenny ${ }^{36}$ demonstrated that, compared to men, women who were matched for body mass and $A_{\mathrm{D}}$ demonstrated a reduced evaporative heat-loss during exercise in a hot-arid environment $\left(35^{\circ} \mathrm{C} ; 12 \% \mathrm{rh}\right)$ at a fixed MHP $(500 \mathrm{~W})$. In a subsequent study, Gagnon and Kenny ${ }^{37}$ examined MHP rates of 200,250 and $300 \mathrm{~W} \cdot \mathrm{m}^{-2}$ of body surface area; a fixed MHP during non-weightbearing exercise (i.e. cycling) negates the influence of differences in body mass, whilst adjusting MHP per unit $A_{\mathrm{D}}$ negates differences in the $A_{\mathrm{D}}$ available for heat exchange. Only at the highest work rate was the evaporative heat-loss less in women than men, due to a lower sweat output per gland. This reduced sweating sensitivity in women is consistent with studies using pharmacological approaches to stimulate sweating in groups of men and women, ${ }^{38}$ and given the controls employed, suggests that, at higher work rates, a 'true' sex difference in sudomotor function exists.

Nevertheless, some of these recent studies have been criticised for investigating a narrow anthropometric range that is not representative of the population ${ }^{12}$ and as such the utility of 
these findings may be limited within a military context. Notley et $a .^{12}$ examined the thermoeffector responses during light $\left(\mathrm{MHP}=135 \mathrm{~W} \cdot \mathrm{m}^{-2}\right)$ and moderate $\left(\mathrm{MHP}=200 \mathrm{~W} \cdot \mathrm{m}^{-2}\right)$ exercise in the heat $\left(28^{\circ} \mathrm{C} ; 36 \% \mathrm{rh}\right)$ in a sample of men and women spanning a wide and overlapping anthropometric range. Using hierarchical multiple linear regression, they demonstrated that, after controlling for body fat, $\mathrm{VO}_{2 \max }$ and mean $T_{\mathrm{b}}$, the $A_{\mathrm{D}} / \mathrm{m}$ ratio explained $10-48 \%$ of the variance in thermoeffector response; small individuals with a higher $A_{\mathrm{D}} / \mathrm{m}$ ratio were more reliant on cutaneous vasomotion whereas larger individuals were more reliant on evaporation of sweat . Furthermore, once the $A_{\mathrm{D}} / \mathrm{m}$ ratio had been accounted for, sex explained $\leq 5 \%$ of variance in thermoeffector response. Thus, in a sample that are anthropometrically representative of the wider population range, thermoeffector function appears more dependent on fitness and anthropometry than sex. However, this study only investigated low and moderate work rates and so direct comparison cannot be made with the lower sweating that has been reported in women at higher work rates. ${ }^{37}$

In summary, women who are representative of the wider military population may be more reliant on cutaneous vasomotion to regulate body temperature, and less reliant on sweating, compared to men. However, this may be mainly due to anthropometric and fitness differences rather than a 'true' sex difference, and these effects could be less pronounced among males and female in GCC roles if anthropometric and fitness differences are less distinct. When studies control for relevant anthropometric factors and fitness, thermoregulatory differences between men and women are diminished, although women may still sweat less than men at higher work rates.

\section{Hormonal influences}

\subsection{Effect of menstrual cycle}

The influence of sex hormone changes over the menstrual cycle on thermoregulation is summarised in a recent review. ${ }^{39}$ Briefly, $T_{\mathrm{C}}$ fluctuates over the course of the menstrual cycle. Oestrogens act on temperature regulating structures within the hypothalamus, increasing the activity of warm sensitive neurons ${ }^{40}$ and lowering the temperature thresholds for sweating and cutaneous vasodilatation. ${ }^{3241}$ Thus, in eumenorrhoeic women, $T_{\mathrm{C}}$ is at its lowest during the latefollicular phase, coincident with the peak in oestrogen concentration. In the mid-luteal phase progesterone concentration is at its highest, which increases the thresholds for cutaneous vasodilatation and sweating, elevating $T_{\mathrm{C}}$ by $\sim 0.5^{\circ} \mathrm{C} .{ }^{32} 4142$ Nevertheless, recent evidence 
employing a whole body direct calorimetry approach suggests that menstrual cycle phase does not appear to affect the rates of whole body heat loss or heat storage across a range of exercise intensities. However, it is important to note that the changes in body heat content during the mid-luteal phase trial occurred in the context of on an elevated initial resting $T_{\mathrm{C}}$ compared to the trials conducted during the early and late follicular phases. ${ }^{43}$ Some studies suggest that there are alterations in thermo-sensation over the menstrual cycle, ${ }^{44} 45$ but any influence on behavioural thermoregulation is poorly understood.

Fluctuations in $T_{\mathrm{C}}$ may be attenuated in trained women, possibly due to their smaller changes in sex hormone concentration during the menstrual cycle, ${ }^{46}$ and thus it might be hypothesised that the physical training undertaken by women in GCC roles may lessen the degree of fluctuation in $T_{\mathrm{C}}$ typically seen over the menstrual cycle. However, there is limited research comparing the thermoregulatory responses of amenorrheal and eumenorrheal women to exercise heat-stress. On the basis of data obtained from a single pair of monozygotic twins (one eumenorrheal and one amenorrheal) Frye et $a l .{ }^{47}$ concluded that there were no thermoregulatory differences during exercise heat-stress. Clearly more research is needed, particularly given the reported prevalence of amenorrhea and dysmenorrhea among military women ${ }^{48}$ and the observation that intense military training may increase the prevalence of menstrual irregularity. ${ }^{49}$ Indeed, data from post-menopausal women suggests that their lower oestrogen levels are associated with an elevated $T_{\mathrm{C}}$, which can be reduced through the effects of exogenous oestrogen therapy lowering the temperature threshold for the heat-loss effector mechanisms. ${ }^{50}$

\subsection{Hormonal contraceptives}

Hormonal contraceptives commonly consist of combined (oestrogens and progestin), or progestin-only formulations. Studies examining the effects of oral hormonal contraceptives on thermoregulation have often used a within-participant design, comparing the placebo or no-pill phase (quasi-follicular) to the contraceptive phase (quasi-luteal). During the contraceptive phase there is an increase in the temperature thresholds for cutaneous vasodilatation and sweating and an elevated $T_{\mathrm{C}}{ }^{51} 5253$ However, the wide variations in oral contraceptive formulation and delivery (e.g. mono, biphasic or triphasic) result in variability in the hormones administered, which may influence their thermoregulatory effects. 
Using a between-groups design, Armstrong et $a .^{54}$ examined the effect of different contraceptive hormones (oral contraceptive [estradiol-progestin] vs. injection [depot medroxyprogesterone acetate] $v s$. no contraceptive) on thermoregulation, before and after 8weeks of heat acclimation and physical training. There were no between-groups differences in thermoregulation before the intervention, whereas after the intervention there were some small differences in thermoregulation, but the authors concluded they were small and did nor impart superior physical fitness or heat acclimation in any group. However, thermoregulatory assessments were only conducted during the follicular or quasi-follicular phase and it is unclear whether the same would be evident at other phases of the menstrual cycle.

\section{Performance}

\subsection{Physical}

A number of studies show women to have a lower tolerance, ${ }^{21} 285556$ or performance level, ${ }^{57}$ than men during exercise in the heat, yet others report no sex differences in terms of tolerance, ${ }^{17}$ or performance decline, ${ }^{58}$ with increasing temperature. Some suggest women have a superior tolerance to heat. ${ }^{22}$ However, as described in Section 2, these conclusions can be influenced by environmental conditions as well as the way in which the study controls factors such as MHP, aerobic fitness and anthropometry.

For example, Wyndham et al. ${ }^{28}$ demonstrated that $8 \%$ of unacclimated women and $50 \%$ of unacclimated men could complete $4 \mathrm{hrs}$ stepping at $1560 \mathrm{ft} \mathrm{lb} \cdot \mathrm{min}^{-1}$ in hot-humid $\left(24^{\circ} \mathrm{C} ; 89\right.$ $\%$ rh) conditions. However, it is unclear if groups were matched for fitness and the women were lighter, resulting in a smaller thermal 'sink'. Lower tolerance times were also shown for women than men during treadmill walking at $25-30 \% \mathrm{VO}_{2 \max }$ in a hot-arid environment $\left(48^{\circ} \mathrm{C} ; 14\right.$ $\%$ rh); although groups were matched for relative $\mathrm{VO}_{2 \max }$ and $A_{\mathrm{D}}$, the women were significantly lighter. ${ }^{21}$ Similarly, McLellan ${ }^{55}$ demonstrated shorter tolerance times for women than men during intermittent walking in uncompensable conditions, whereas Dill et al. ${ }^{57}$ demonstrated that men could complete 30-60 minute walks at a faster pace in 'desert heat' than women.

In contrast, Horstman and Christensen ${ }^{17}$ demonstrated no sex difference in the tolerance to cycling at $40 \% \mathrm{VO}_{2 \max }$ in hot-arid conditions $\left(45^{\circ} \mathrm{C} ; 14 \% \mathrm{rh}\right)$ although estimations of MHP suggest that this may have been lower in the women than men. Likewise, Avellini et al. ${ }^{22}$ reported that the tolerance of women during the pre-ovulatory stage of the menstrual cycle was 
superior to that of men during treadmill walking $\left(5.6 \mathrm{~km} \cdot \mathrm{h}^{-1} ; 2 \%\right.$ gradient $)$ at $36^{\circ} \mathrm{C}, 65 \% \mathrm{rh}$. Although the women had a lower $\mathrm{VO}_{2 \max }$ (relative and absolute) and higher body fat percentage, the groups were not statistically different for mass, $A_{\mathrm{D}}$, or $A_{\mathrm{D}} / \mathrm{m}$ ratio. However, the women were, on average, $\sim 7 \mathrm{~kg}$ lighter with a larger $A_{\mathrm{D}} / \mathrm{m}$ ratio $\left(+14.7 \mathrm{~cm}^{2} \cdot \mathrm{kg}^{-1}\right)$, which could be advantageous in humid conditions. ${ }^{10}$ Furthermore, there were no sex differences in tolerance during the post-ovulatory phase. Others have also suggested that heat tolerance changes across the menstrual cycle, being reduced in the mid-luteal phase relative to the follicular phase,,$^{22} 42$ although some studies have shown no differences..$^{21} 59$

Given the varying experimental controls in the aforementioned studies it is unclear to what extent the reported differences were attributable to fitness, anthropometry, or sex. Kazman et $a l .{ }^{56}$ compared 55 men and 20 women during treadmill walking $\left(5 \mathrm{~km} \cdot \mathrm{h}^{-1} ; 2 \%\right.$ grade $)$ for up to 120 minutes at $40^{\circ} \mathrm{C}$ and $40 \% \mathrm{rh}$. Heat intolerance was defined as attaining a heart rate $>150$ beats.minute ${ }^{-1}$ or $T_{\mathrm{C}}>38.5^{\circ} \mathrm{C}$. Using hierarchical regression analysis, it was reported that women were 3.7 times more likely to be classified as heat intolerant than men. However, heat intolerant participants also had lower relative and absolute $\mathrm{VO}_{2 \max }$ and higher body fat percentage. Importantly, when these variables were entered into the regression equation sex became non-significant as a predictor of tolerance, indicating that the 'sex differences' were largely due to fitness and anthropometry rather than sex, per se.

Heat acclimation may influence sex differences in physical performance in the heat. Wyndham et $a{ }^{28}$ and Avellini et al. ${ }^{22}$ reported that the thermoregulatory responses of men and women during exercise in humid-heat were more similar post-acclimation, with all participants subsequently able to complete the exercise tasks ( $4 \mathrm{hrs}$ stepping and $3 \mathrm{hrs}$ treadmill walking, respectively). However, differences in sweating rate, which in each case was lower in women pre-acclimation, remained, ${ }^{28}$ or increased. ${ }^{22}$ Moreover, in the study of Wyndham et al. ${ }^{28}$ the pre-acclimation thermoregulatory strain was higher in women, but in Avellini et al. ${ }^{22}$ the converse was true, whereas completion of the exercise tests does not enable evaluation of the limits of tolerance. Frye and Kamon ${ }^{21}$ also reported that thermoregulatory function, including sweating, was more similar between sexes during exercise in a hot-arid environment postacclimation, with all participants now able to complete a 3-hr treadmill walk. Finally, Horstman $\&$ Christensen ${ }^{17}$ reported that the sweat rate and sensitivity of women increased with heat acclimation whereas men's remained unchanged. Women also demonstrated a greater reduction in $T_{\text {re }}$ and heart rate, and although exercise tolerance was no different between men 
and women pre-acclimation, post-acclimation the women had a significantly longer tolerance time. More recent data also supports the possibility of sex differences in the pattern of heat acclimation, with women demonstrating a more rapid sudomotor adaption than men, but taking longer to achieve thermal and cardiovascular stability. ${ }^{60}$

Overall, the data examining sex differences in physical performance in the heat, before and after acclimation, are somewhat equivocal and it is difficult to draw firm conclusions. Many of these studies are underpowered and the findings heavily influenced by the variations in experimental design. The relevance of some studies within a military, or GCC, context is limited. In keeping with the thermoregulatory research, some more recent data suggests that the average women may be more intolerant to hot-dry environments than the average man, but these 'sex differences' are primarily due to the effects fitness and anthropometry rather than sex, per se. As such, they could be diminished in a GCC cohort, but further research is required to verify this hypothesis.

\subsection{Cognitive}

Numerous studies have shown that heat stress negatively effects cognitive tasks, including those with particular relevance for military roles, such as vigilance, ${ }^{61}$ working and visual memory, ${ }^{62} 63$ executive tasks, ${ }^{64}$ and task planning. ${ }^{65}$ However, others (e.g. Amos et al. ${ }^{66}$ ) have shown no effect of heat stress on aspects of cognitive performance. The broad consensus from recent reviews appears to be that simple cognitive tasks may be less vulnerable to heat stress than more complex tasks. ${ }^{67} 68$

There is limited research examining sex differences in cognitive performance in the heat. Wyon et al. ${ }^{69}$ demonstrated that performance of some cognitive tasks (e.g. sentence comprehension, recognition memory) declined in both sexes beyond an ambient temperature of $\sim 27^{\circ} \mathrm{C}$. However, in a multiplication task, the female participants maintained performance beyond $28^{\circ} \mathrm{C}$, whereas the performance of males declined. It was suggested that this was due to a higher thermal discomfort in the men, although this is at odds with research suggesting that there is no sex-effect on thermal comfort. ${ }^{27}$ It has also been speculated that the influence of heat stress on cognition might be related to the initial skill level, ${ }^{67}$ men may have better visuo-spatial and mathematical abilities than women, ${ }^{70}$ whereas women may have superior verbal skills. ${ }^{71}$ Gaoua $^{67}$ also highlights sex differences in neurotransmitters which could influence arousal, and potentially affect cognitive performance. However, these assertions are largely speculative and 
further research, utilising cognitive tasks that have relevance within the military context, is needed to understand the influence of sex on cognitive performance in the heat.

\section{Heat illness}

Heat illness encompasses a spectrum of conditions ranging from light-headedness through to heat stroke and death. Between 2006 and 2010, 25.5 men and 12.7 women per 100,000 population, per year, presented to USA Emergency Departments with heat illness not requiring admission. ${ }^{72}$ Similarly, the incidence of heat-related illnesses requiring Emergency Department visitations in Florida is higher in men than women during summer months, with a crude rate ratio of 5.91 per 100,000 worker years and 2.77 per 100,000 person years for work, and nonwork heat-related illnesses, respectively. ${ }^{73}$ The Centers for Disease Control and Prevention $\mathrm{USA}^{74}$ reported 2,271 male and 1,135 female deaths from extreme heat exposure between 1999 and 2003 , with a death rate of 0.8 per million population in men and 0.3 per million population in women during an extreme heat event in $2012 .{ }^{75}$ In Adelaide, South-Australia, 36 male and 18 female deaths were reported during a 2009 heat-wave, ${ }^{76}$ whereas between 2006 and 2010, 0.024 men and 0.006 women per 100,000 population, per year, died in Emergency Departments in the USA from heat-related illness. ${ }^{72}$ Among military populations, heat stroke rates are higher in men than in women soldiers, although the rates of other heat illness were higher in women than men. ${ }^{77}$

The reasons for the reported sex differences in heat illness rates are not clear, and possibly contrary to that which might be expected based upon the thermoregulatory differences between men and women described in section 3.2. Heat stroke has an inflammatory component occurring in the context of an elevated $T_{\mathrm{C}},{ }^{78}$ but recent research suggests that sex has no effect on intestinal epithelial injury and permeability, and minimal effect on the systemic cytokine response to exertional heat stress. ${ }^{79}$ Alternatively, incidence analyses may not take into account differences in the type of activity that have historically been undertaken by men and women, which might demand different rates of MHP, or levels of heat exposure. There may also be relevant behavioural differences; women demonstrate more circumspect attitude towards the health effects of high heat and more precautionary behaviours than men. ${ }^{80}$ However, for individuals operating in GCC roles the opportunity to undertake sex-specific physical activities and exercise sex-dependent precautionary behaviours will be limited, and thus the relevance of these data in a GCC context is unclear. 


\section{Summary}

The factors underpinning population level sex differences in males and females in response to exercise heat-stress are summarised in table 1. 'True' sex differences in thermoregulation between men and women are relatively limited, and appear confined to lower sweat rates at higher work rates. Nevertheless, relative to male soldiers, female soldiers are, on average, less aerobically fit, lighter, with a smaller $A_{\mathrm{D}}$ and a higher $A_{\mathrm{D}} / \mathrm{m}$ ratio and percentage body fat. These differences may increase the cardiovascular strain of a given task, reduce the rate of heat exchange with the environment, increase reliance on vasomotor changes to regulate body temperature, and lessen the size of the thermal 'heat sink'. Moreover, women may be at a greater thermoregulatory disadvantage during the mid-luteal phase of the menstrual cycle, although some recent data challenges this assertion. However, during load-bearing exercise, lighter individuals have a lower MHP. Overall, these factors mean that, relative to men, women who are representative of the wider military population might be at a thermoregulatory disadvantage in many hot environments, particularly at higher work rates in hot-arid conditions, but this may be lessened in conditions favouring a high $A_{\mathrm{D}} / \mathrm{m}$ ratio, where higher sweat rates are of little benefit (hot-humid).

The purported thermoregulatory differences between men and women are consistent with some studies examining sex differences in physical performance in the heat, although there are inconsistencies between studies. Any sex differences may be secondary to the influences of fitness and anthropometric factors and might be lessened with heat acclimation. Heat illness incidence data appear at odds with the apparent thermoregulatory differences between men and women i.e. lower heat illness and/or heat stroke incidence in women than men. However, some analyses may not adequately account for sex differences in activity profiles and exposure risk.

Finally, it is important to acknowledge that women who pass current and future gender-free physical employment standards to undertake GCC roles may be fitter, with a lower fat mass than the average female soldier. If they are more similar to their male counterparts then the thermoregulatory and performance differences attributed primarily to fitness and some anthropometric factors may be diminished. Likewise the opportunities for sex differences in activity profiles and exposure risk for those operating GCC roles are likely to be limited, which may limit the relevance of much of the extant heat-illness incidence data. In many areas the 
literature is of poor quality and does not examine individual's representative of those operating in military roles, undertaking relevant tasks at an appropriate pace, in representative environmental conditions, whilst wearing appropriate operational equipment. In some areas, e.g. behavioural thermoregulation and cognition, further work is urgently required to adequately understand sex differences in the heat that are relevant within a GCC context

\section{Acknowledgements}

This review is adapted from a review of literature supported by the ASC (Analysis Support Construct) BAE Systems (Operations) Ltd. The authors would like to thank Dr Julie Greeves and Dr Thomas O'Leary for their assistance in the preparation on this manuscript.

\section{References}

1 Ministry of Defence. Interim Report on the Health Risks to Women in Ground Close Combat Roles.

https://assets.publishing.service.gov.uk/government/uploads/system/uploads/attachment data /file/536381/20160706_ADR006101_Report_Women in Combat_WEB-FINAL.PDF, 2016.

2 Ministry of Defence. UK Armed Forces Biannual Diversity Statistics. https://assets.publishing.service.gov.uk/government/uploads/system/uploads/attachment data /file/712124/Biannual_Diversity_Statistics_Apr18.pdf, 2018.

3 Ministry of Defence. Women in ground close combat (GCC) Review paper: 1 December 2014 , https://assets.publishing.service.gov.uk/government/uploads/system/uploads/attachment data /file/389575/20141218 WGCC Findings Paper_Final.pdf, 2014

4 American College of Sports Medicine. ACSM's Guidelines for Exercise Testing and Prescription. $8^{\text {th }}$ edn. Lippincott, Williams \& Wilkins, 2010.

5 Allsopp A, Scarpello E, Andrews S, et al. Survival of the fittest? The scientific basis for the Royal Navy pre-joining fitness test. JR Nav Med Serv 2003; 89: 11-18.

6 Havenith G, Coenen JM, Kistemaker L, et al. Relevance of individual characteristics for human heat stress response is dependent on exercise intensity and climate type. Eur J Appl Physiol Occup Physiol 1998; 77: 231-241.

7 Cramer MN, Jay O. Biophysical aspects of human thermoregulation during heat stress. Auton Neurosci 2016; 196: 3-13.

8 Cramer MN, Jay O. Explained variance in the thermoregulatory responses to exercise: the independent roles of biophysical and fitness/fatness-related factors. $J$ Appl Physiol 2015; 119 : 982-989.

9 Passmore R, Durnin JV. (1955). Human energy expenditure. Physiol Rev. 35(4), 801-40. 
10 Shapiro Y, Pandolf KB, Avellini BA, et al. Physiological responses of men and women to humid and dry heat. J Appl Physiol Respir Environ Exerc Physiol 1980; 49:1-8

11 Marino FE, Mbambo Z, Kortekaas E, et al. Advantages of smaller body mass during distance running in warm, humid environments. Pflugers Arch 2000; 441: 359-67.

12 Notley SR, Park J, Tagami K, et al. Variations in body morphology explain sex differences in thermoeffector function during compensable heat stress. Exp Physiol 2017; 102: 545-562.

13 Heinicke K, Wolfarth B, Winchenbach P, et al. Blood volume and hemoglobin mass in elite athletes of different disciplines. Int J Sports Med 2001; 22(7): 504-12.

14 Kenney WL. A review of comparative responses of men and women to heat stress. Environ Res 1985; 37: 1-11.

15 Lamarche DT, Notley SR, Louie JC, et al. Fitness-related differences in the rate of wholebody evaporative heat loss in exercising men are heat-load dependent. Exp Physiol 2018; 103(1): 101-110.

16 Paolone AM, Wells CL, Kelly GT. Sexual variations in thermoregulation during heat stress. Aviat Space Environ Med 1978; 49: 715-719.

17 Horstman DH, Christensen E. Acclimatization to dry heat: active men vs. active women. $J$ Appl Physiol Respir Environ Exerc Physiol. 1982; 52: 825-3.1

18 Ichinose-Kuwahara T, Inoue Y, Iseki Y et al. Sex differences in the effects of physical training on sweat gland responses during a graded exercise. Exp Physiol 2010; 95: 1026-32

19 Schwiening CJ, Mason MJ, Thompson M. Absolute power, not sex, promotes perspiration. Exp Physiol 2011; 96(5): 556-8;

20 Gagnon D, Kenny GP. Does sex have an independent effect on thermoeffector responses during exercise in the heat? J Physiol 2012; 590: 5963-5973.

21 Frye AJ, Kamon E. Responses to dry heat of men and women with similar aerobic capacities. J Appl Physiol Respir Environ Exerc Physiol 1981; 50: 65-70.

22 Avellini BA, Kamon E, Krajewski JT. Physiological responses of physically fit men and women to acclimation to humid heat. J Appl Physiol Respir Environ Exerc Physiol 1980; 49: 254-61.

23 Cabanac M, Serres P. Peripheral heat as a reward for heart rate response in the curarized rat. J Comp Physiol Psychol 1976; 90: 435-41.

24 Flouris AD, Schlader ZJ. Human behavioral thermoregulation during exercise in the heat. Scand J Med Sci Sports. 2015; 25S: 52-64.

25 Golja P, Tipton MJ, Mekjavic IB. Cutaneous thermal thresholds - the reproducibility of their measurements and the effect of gender. J Thermal Biol 2003; 28: 341-346. 
26 Gerrett N, Ouzzahra Y, Coleby S, et al. Thermal sensitivity to warmth during rest and exercise: a sex comparison. Eur J Appl Physiol 2014; 114: 1451-62.

27 Ciuha U, Mekjavic IB. Regional thermal comfort zone in males and females. Physiol Behav 2016; 161: 123-129.

28 Wyndham $\mathrm{CH}$. Role of skin and of core temperatures in man's temperature regulation. $J$ Appl Physiol 1965; 20: 31-36.

29 Hardy JD, Du Bois EF. (1940). Differences between Men and Women in Their Response to Heat and Cold. Proc Natl Acad Sci USA 1940; 26: 389-98.

30 Fox RH, Löfstedt BE, Woodward PM, et al. Comparison of thermoregulatory function in men and women. $J$ Appl Physiol 1969; 26:444-53.

31 Cunningham DJ, Stolwijk JA, Wenger CB. Comparative thermoregulatory responses of resting men and women. J Appl Physiol Respir Environ Exerc Physiol 1978; 45: 908-15.

32 Inoue Y, Tanaka Y, Omori K, et al. Sex- and menstrual cycle-related differences in sweating and cutaneous blood flow in response to passive heat exposure. Eur J Appl Physiol 2005; 94: 323-32.

33 Keatisuwan W, Ohnaka T, Tochihara Y. Physiological responses of men and women during exercise in hot environments with equivalent WBGT. Appl Hum Sci 1996; 15: 249-258.

34 Morimoto T, Slabochova Z, Naman RK, et al. Sex differences in physiological reactions to thermal stress. J Appl Physiol 1967; 22: 526-532.

35 Weinman KP, Slabochova Z, Bernauer EM, et al. Reactions of men and women to repeated exposure to humid heat. J Appl Physiol 1967; 22: 533-8.

36 Gagnon D, Kenny GP. Sex modulates whole-body sudomotor thermosensitivity during exercise. J Physiol. 2011; 589: 6205-17.

37 Gagnon D, Kenny GPSex differences in thermoeffector responses during exercise at fixed requirements for heat loss. J Appl Physiol 2012; 113: 746-57.

38 Gagnon D, Crandall CG, Kenny GP. Sex differences in postsynaptic sweating and cutaneous vasodilation. J Appl Physiol 2013; 114: 394-401.

39 Charkoudian N, Stachenfeld N. Sex hormone effects on autonomic mechanisms of thermoregulation in humans. Auton Neurosci 2016; 196:75-80.

40 Silva NL, Boulant JA. Effects of testosterone, estradiol, and temperature on neurons in preoptic tissue slices. Am J Physiol 1986; 250: R625-632.

41 Stephenson LA, Kolka MA. Menstrual cycle phase and time of day alter reference signal controlling arm blood flow and sweating. Am J Physiol 1985; 249: R186-191. 
42 Janse De Jonge XA, Thompson MW, Chuter VH, et al. Exercise performance over the menstrual cycle in temperate and hot, humid conditions. Med Sci Sports Exerc 2012; 44: 21908.

43 Notley SR, Dervis S, Poirier MP, et al. Menstrual cycle phase does not modulate whole body heat loss during exercise in hot, dry conditions. J Appl Physiol 2019; 126:286-293.

44 Scarperi M, Bleichert A. Non-thermal influences on thermoregulatory behaviour. J Thermal Biol 1983; 8:179-181.

45 Shoemaker JA, Refinetti R. Day-night difference in the preferred ambient temperature of human subjects. Physiol Behav 1996; 59: 1001-1003.

46 Kuwahara $\mathrm{T}$, Inoue $\mathrm{Y}$, Abe $\mathrm{M}$, et al. Effects of menstrual cycle and physical training on heat loss responses during dynamic exercise at moderate intensity in a temperate environment. Am J Physiol Regul Integr Comp Physiol 2005; 288: R1347-1353.

47 Frye AJ, Kamon E, Webb M. Responses of menstrual women, amenorrheal women, and men to exercise in a hot, dry environment. Eur J Appl Physiol Occup Physiol 1982; 48:279-88.

48 Gifford RM, Reynolds RM, Greeves J, et al. Reproductive dysfunction and associated pathology in women undergoing military training. $J$ R Army Med Corps 2017; 163:301-310.

49 Cho GJ, Han SW, Shin JH, et al. Effects of intensive training on menstrual function and certain serum hormones and peptides related to the female reproductive system. Medicine (Baltimore) 2017; 96:e6876.

50 Brooks EM, Morgan AL, Pierzga JM, et al. Chronic hormone replacement therapy alters thermoregulatory and vasomotor function in postmenopausal women. J Appl Physiol 1997; 83: 477-84.

51 Charkoudian N, Johnson JM. Modification of active cutaneous vasodilation by oral contraceptive hormones. J Appl Physiol 1997; 83: 2012-2018.

52 Tenaglia SA, McLellan TM, Klentrou PP. Influence of menstrual cycle and oral contraceptives on tolerance to uncompensable heat stress. Eur J Appl Physiol Occup Physiol 1999; 80: 76-83.

53 Martin JG, Buono MJ. Oral contraceptives elevate core temperature and heart rate during exercise in the heat. Clin Physiol 1997; 17: 401-408.

54 Armstrong LE, Maresh CM, Keith NR, et al. Heat acclimation and physical training adaptations of young women using different contraceptive hormones. Am J Physiol Endocrinol Metab 2005; 288: E868-875.

55 McLellan TM. Sex-related differences in thermoregulatory responses while wearing protective clothing. Eur J Appl Physiol Occup Physiol 1998; 78: 28-37.

56 Kazman JB, Purvis DL, Heled Y, et al. Women and exertional heat illness: identification of gender specific risk factors. US Army Med Dep J 2015; Apr-Jun: 58-66. 
57 Dill DB, Soholt LF, McLean DC, et al. Capacity of young males and females for running in desert heat. Med Sci Sports 1977; 9: 137-142.

58 Ely MR, Cheuvront SN, Roberts WO, et al. Impact of weather on marathon-running performance. Med Sci Sports Exerc 2007; 39: 487-493.

59 Sunderland C, Nevill M. Effect of the menstrual cycle on performance of intermittent, highintensity shuttle running in a hot environment. Eur J Appl Physiol 2003; 88: 345-352.

60 Mee JA, Gibson OR, Doust J, et al. A comparison of males and females' temporal patterning to short- and long-term heat acclimation. Scand J Med Sci Sports 2015;25 Suppl 1: 250-8.

61 Kobrick J.L. Johnson RF. Effects of hot and cold environments on military performance. In: Gal R, Mangelsdorff AD, eds. Handbook of Military Psychology. Wiley, 1991

62 Gaoua N, Racinais S, Grantham J, et al. Alterations in cognitive performance during passive hyperthermia are task dependent. Int J Hyperthermia 2011; 27: 1-9.

63 Racinais S, Gaoua N, Grantham J. Hyperthermia impairs short-term memory and peripheral motor drive transmission. $J$ Physiol 2008; 586: 4751-4762.

64 McMorris T, Swain J, Smith, M, et al. Heat stress, plasma concentrations of adrenaline, noradrenaline, 5-hydroxytryptamine and cortisol, mood state and cognitive performance. Int J Psychophysiol 2006; 61: 204-215.

65 Gaoua N, Grantham J, Racinais S, et al. Sensory displeasure reduces complex cognitive performance in the heat. J Environ Psychol 2012; 32: 158-163.

66 Amos D, Hansen R, Lau WM, et al. Physiological and cognitive performance of soldiers conducting routine patrol and reconnaissance operations in the tropics. Mil Med 2000; 165: 961-966.

67 Gaoua N. Cognitive function in hot environments: a question of methodology. Scand J Med Sci Sports 2010; S3: 60-70.

68 Taylor L., Watkins SL, Marshall H, et al. The impact of different environmental conditions on cognitive function: a focused review. Front Physiol 2016; 6: 372.

69 Wyon DP, Andersen IB., Lundqvist GR. The effects of moderate heat stress on mental performance. Scand J Work Environ Health 1979; 5(4): 352-361.

70 Benbow CP. Sex differences in mathematical reasoning ability in intellectually talented preadolescents: Their nature, effects, and possible causes. Behav Brain Sci 1988; 11: 169-183.

71 de Courten-Myers GM. The human cerebral cortex: gender differences in structure and function. J Neuropathol Exp Neurol 1999; 58: 217-226. 
72 Hess JJ, Saha S, Luber G. Summertime acute heat illness in U.S. emergency departments from 2006 through 2010: analysis of a nationally representative sample. Environ Health Perspect 2014; 122: 1209-1215

73 Harduar Morano L, Watkins S, Kintziger K. A Comprehensive Evaluation of the Burden of Heat-Related Illness and Death within the Florida Population. Int J Environ Res Public Health 2016; 13: E551.

74 Centers for Disease Control and Prevention. Heat-related deaths United States, 1999-2003. MMWR Morb Mortal Wkly Rep 2006; 55: 796-798.

75 Centers for Disease Control and Prevention Heat-related deaths after an extreme heat eventfour states, 2012, and United States, 1999-2009. MMWR Morb Mortal Wkly Rep 2013; 62: 433-436.

76 Herbst J, Mason K, Byard RW, et al. Heat-related deaths in Adelaide, South Australia: review of the literature and case findings - an Australian perspective. J Forensic Leg Med 2014; 22: $73-78$.

77 Armed Forces Health Surveillance Bureau. Update: Heat illness, active component, U.S. Armed Forces, 2016. MSMR 2017; 24: 9-13.

78 Leon LR, Helwig BG. Heat stroke: role of the systemic inflammatory response. J Appl Physiol 2010; 109: 1980-1988.

79 Snipe RMJ, Costa RJS. Does biological sex impact intestinal epithelial injury, small intestine permeability, gastrointestinal symptoms and systemic cytokine profile in response to exertional-heat stress? J Sports Sci 2018; 36:2827-2835.

80 Khare S, Hajat S, Kovats S, et al. (2015). Heat protection behaviour in the UK: results of an online survey after the 2013 heatwave. BMC Public Health 2015; 15: 878.

\section{Tables}

Table 1: Summary of factors underpinning population level sex differences in males and females in response to exercise heat-stress. 


\begin{tabular}{|c|c|c|}
\hline Factor & Difference & Significance \\
\hline \multicolumn{3}{|l|}{ Anthropometric } \\
\hline Mass & Lower in females than males & $\begin{array}{l}\text { Low body mass reduces the size of the 'heat sink', resulting in a bigger body temperature increase for a given heat } \\
\text { storage. Those with a low body mass have lower metabolic heat production during load bearing exercise. }\end{array}$ \\
\hline Body composition & $\begin{array}{l}\text { Higher percent body fat in } \\
\text { females than males }\end{array}$ & $\begin{array}{l}\text { The heat specific capacity of adipose tissue is less than 'lean' tissue. Individuals with higher body fat percentage } \\
\text { will have a greater increase in body temperature for a given change in heat content. }\end{array}$ \\
\hline Body surface area & Lower in females than males & $\begin{array}{l}\text { Heat-transfer potential with environment is lower with a small body surface area. May be disadvantageous in } \\
\text { conditions favouring heat loss or beneficial in conditions favouring heat gain from the environment }\end{array}$ \\
\hline $\begin{array}{l}\text { Body surface area: } \\
\text { mass }\left(A_{\mathrm{D}} / \mathrm{m}\right) \text { ratio }\end{array}$ & $\begin{array}{l}\text { Higher in females than } \\
\text { males }\end{array}$ & $\begin{array}{l}\text { High } A_{\mathrm{D}} / \mathrm{m} \text { ratio affords a large surface are for heat exchange relative to metabolic heat production which may result } \\
\text { in lower heat production and less heat storage in some hot environments. May affect heat loss mechanisms (see } \\
\text { vasomotion, below). }\end{array}$ \\
\hline \multicolumn{3}{|l|}{ Fitness } \\
\hline $\mathrm{VO}_{2 \max }$ & Lower in females than males & $\begin{array}{l}\text { At a given absolute work rate competition between muscle and skin for blood flow is greater in those with a low } \\
\mathrm{VO}_{2 \max } \text {, this increases the cardiovascular component of thermoregulation. Sweating is lower at high work rates in } \\
\text { those with a low } \mathrm{VO}_{2 \max }\end{array}$ \\
\hline \multicolumn{3}{|l|}{ Thermoregulatory } \\
\hline $\begin{array}{l}\text { Behavioural } \\
\text { thermoregulation }\end{array}$ & $\begin{array}{l}\text { Females may be more } \\
\text { sensitive to heat than males }\end{array}$ & $\begin{array}{l}\text { Some limited evidence to support greater female sensitivity to heat, but does not appear to affect upper limit of } \\
\text { thermal comfort. Effect on behavioural thermoregulation (if any) is unclear. }\end{array}$ \\
\hline Vasomotion & $\begin{array}{l}\text { May be more important in } \\
\text { females than males }\end{array}$ & A high $A_{\mathrm{D}} / \mathrm{m}$ ratio may increase the reliance on vasomotion for heat loss. \\
\hline Sudomotion & $\begin{array}{l}\text { Possibly lower in females } \\
\text { than males at high work } \\
\text { rates }\end{array}$ & $\begin{array}{l}\text { Sweating rates may be lower in females than males during exercise at high work rates, even when key } \\
\text { anthropometric differences are controlled for. }\end{array}$ \\
\hline \multicolumn{3}{|l|}{ Hormonal } \\
\hline $\begin{array}{l}\text { Female sex } \\
\text { hormones }\end{array}$ & N/A & $\begin{array}{l}\text { Deep body temperature is highest }\left(+0.5^{\circ} \mathrm{C}\right) \text { in the mid-luteal and lowest in late follicular phase of the menstrual } \\
\text { cycle due to changes in concentration of oestrogen and progesterone. Some evidence that this may not adversely } \\
\text { affect heat loss or storage during exercise. }\end{array}$ \\
\hline
\end{tabular}

